\title{
c-Met expression in primary tumors and their corresponding distant metastases
}

\author{
MARTIN ISAKSSON-METTÄVAINIO ${ }^{1}$, BETHANY VAN GUELPEN ${ }^{1}$, ÅKE ÖBERG $^{2}$, \\ ROGER STENLING $^{1}$, RICHARD PALMQVIST ${ }^{1}$ and MARIA L. HENRIKSSON ${ }^{1}$ \\ Departments of ${ }^{1}$ Medical Biosciences, Pathology, and ${ }^{2}$ Perioperative and Surgical Sciences, \\ Surgery, Umeå University, SE-901 85 Umeå, Sweden
}

Received June 27, 2008; Accepted September 4, 2008

DOI: $10.3892 / \mathrm{mmr} 00000029$

\begin{abstract}
Met is a receptor tyrosine kinase that has been implicated in the pathogenesis and growth of a wide variety of human malignancies, including $\mathrm{CRC}$, but its role in metastasis is largely unknown. We compared c-Met expression in primary human colorectal carcinomas and distant metastases from the same patients. Formalin-fixed paraffin-embedded tissue samples from 69 colorectal cancer patients were obtained. The protein expression of c-Met was evaluated immunohistochemically using a commercial antibody. The difference in expression between primary tumors and their corresponding distant metastases was analyzed using the Wilcoxon signedrank test. c-Met expression was statistically significantly lower in the distant metastases compared to their corresponding primary tumors $(\mathrm{p}<0.001)$, whereas no difference was found between lymph node metastases and their corresponding primary tumors $(\mathrm{p}=0.957)$. The degree of $\mathrm{c}$-Met expression was not related to clinicopathological characteristics such as tumor grade and Dukes' stage at the time of primary tumor diagnosis, or to the location of the distant metastases. We demonstrated that c-Met expression is often reduced in distant metastases compared to their corresponding primary colorectal tumors. Additional studies of c-Met activation and signal transduction will increase our knowledge about the role of c-Met in colorectal cancer metastasis.
\end{abstract}

\section{Introduction}

Colorectal cancer (CRC) is the third leading cause of death in the western world with an overall 5-year survival of $<60 \%$. Succumbing to CRC is usually due to distant metastatic spread, with the liver being the most common site. Once distant metastases have been established, the chances of

Correspondence to: Dr Maria L. Henriksson, Department of Medical Biosciences and Pathology, Umeå University, SE-901 85 Umeå, Sweden

E-mail: maria.henriksson@medbio.umu.se

Key words: c-Met, colorectal cancer, metastasis long-term survival are very low. Therefore, achieving an understanding of the molecular mechanisms contributing to the metastatic ability of a colorectal carcinoma is critical to the development of effective treatments.

c-Met is a receptor tyrosine kinase that has been implicated in the pathogenesis and growth of a wide variety of human malignancies (1-3), including CRC (4-6). c-Met expression in colonic cells increases during the progression towards malignancy (7), and a higher c-Met expression has been observed in colorectal tumors compared with corresponding normal colon mucosa (8).

The heterodimeric c-Met protein (9) is activated by hepatocyte growth factor (HGF), also known as scatter factor (SF) (9). The binding of HGF/SF to c-Met is known to promote motility, morphogenesis and mitogenesis in epithelial cell lines of various origins $(10,11)$, causing colon cancer cells to form crypt-like structures (10) and inducing angiogenesis in endothelial cells (5).

The c-Met signaling pathway is believed to stimulate tumor invasion and metastasis. The Madkin-Darby canine kidney (MDCK) cell line responds to HGF/SF by colony dispersal and epithelial-to-mesenchymal transition (EMT), increasing cell motility and the invasion of collagen matrices (12). c-Met stimulation by HGF/SF from stromal cells has been suggested to facilitate local invasion of epithelial cells (13).

In CRC, it has been suggested that c-Met is overexpressed in metastatic spread $(14,15)$, and that it may be used as a marker of lymph node metastases (8). However, despite increasing evidence for a role of c-Met in CRC metastasis, only two small ( $n=6$ and $n=10$, respectively) studies have, to our knowledge, compared c-Met expression in primary CRCs and distant metastases, with conflicting results $(16,17)$.

This study aimed to examine the degree of c-Met expression in 69 primary human colorectal carcinomas in relation to c-Met expression in distant metastases from the same patients.

\section{Materials and methods}

Patients. Sixty-nine CRC patients with archival tissue from a primary colorectal adenocarcinoma and at least one distant metastasis were included in the study. Patients were identified using the computerized patient record database at the 
Table I. Characteristics of colorectal cancer patients and tumors at time of diagnosis.

\begin{tabular}{|c|c|c|}
\hline & No. of patients & $\%$ \\
\hline \multicolumn{3}{|l|}{ Age, years } \\
\hline$<50$ & 10 & 14.5 \\
\hline $51-60$ & 12 & 17.4 \\
\hline $61-70$ & 26 & 37.7 \\
\hline$>70$ & 21 & 30.4 \\
\hline \multicolumn{3}{|l|}{ Sex } \\
\hline Male & 40 & 58.0 \\
\hline Female & 29 & 42.0 \\
\hline \multicolumn{3}{|c|}{ Dukes' stage ${ }^{a}$} \\
\hline A & 1 & 1.4 \\
\hline B & 23 & 33.3 \\
\hline $\mathrm{C}$ & 43 & 62.3 \\
\hline NA & 2 & 2.9 \\
\hline \multicolumn{3}{|l|}{ Grade } \\
\hline High & 10 & 14.5 \\
\hline Moderate & 54 & 78.3 \\
\hline Low & 5 & 7.2 \\
\hline \multicolumn{3}{|l|}{ Mucinous } \\
\hline Yes & 14 & 20.3 \\
\hline No & 55 & 79.7 \\
\hline
\end{tabular}

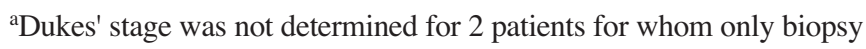
tissue was available.

Department of Clinical Pathology, University Hospital, Umeå, Sweden. Patients diagnosed between the years 1982, when the computerized database was implemented, and 2000 were included. Staging and grading of the tumors were performed by pathologists at the time of surgery or biopsy. This study was approved by the Research Ethics Committee of Umeå University, Umeå, Sweden.

Immunohistochemistry. Formalin-fixed paraffin-embedded routine diagnostic tissue blocks were used to prepare slides. Tissue sections (4- $\mu \mathrm{m})$ were cut, mounted on objective slides, deparaffinized, rehydrated and heated in EDTA ( $\mathrm{pH}$ 8.0) in a microwave for $3 \times 5 \mathrm{~min}$. The Dako EnVision ${ }^{\mathrm{TM}}$ system (Dako Corp., Carpinteria, CA) was used to visualize the bound c-Met antibody, which was purchased from Zymed, CA, USA.

Expression of c-Met, localized in the cytoplasm and outer cellular membrane of colorectal tumor cells, was graded based on the intensity of immunohistochemical staining in the entire tumor. A four-level scale was employed: -, negative; +/-, very weak; +, medium; and ++ , strong positive staining, according to Takeuchi et al (8). Samples were evaluated twice by the same observer, who was blinded to the details of the patients and samples. Intra-observer disagreements were reviewed a third time, followed by a conclusive judgment.
Table II. Localization of primary tumors and their corresponding distant metastases.

Localization of primary tumors $(\%)$

Right colon

Left colon

Rectum

Recto-sigmoid junction

Unspecified

Localization of distant metastases (\%)

Liver

Lung

CNS

Skeletal

Skin

Ovarian

Peritoneum

Gall bladder

Scar in abdominal wall

$10(14.5)$

Statistical analysis. The Wilcoxon signed-rank test, a nonparametric paired test, was used to compare c-Met expression in primary tumors and their corresponding metastasis. Tests were two-sided, and a p-value of $<0.05$ was considered statistically significant.

\section{Results}

Details of the patients and tumors are presented in Table I. A total of 69 cases (40 men and 29 women), aged 36-85 years (median 64) at CRC diagnosis, met the inclusion criteria for the study. The distant metastases were diagnosed up to 6 months prior to, and up to 7 years after, diagnosis of the primary tumor. For 43 patients, tissue samples were available from lymph node metastases obtained at the surgical resection of the primary tumor.

Locations of the tumors and metastases are presented in Table II. Of the 69 primary tumors, 16 were located in the proximal colon, 25 in the distal colon and 23 in the rectum. The majority of the corresponding distant metastases were located in the liver (35 samples), followed by lung, central nervous system, bone, and skin (5 samples each). Less common sites included the peritoneum, gall bladder and ovary. In 10 patients, metastases were due to local recurrence in the surgical scar.

The distribution of primary tumors, lymph node metastases and distant metastases according to c-Met protein expression is presented in Table III, and the relationship between the primary tumors and their corresponding distant metastases is shown in Fig. 2. The degree of c-Met expression was statistically significantly lower in the distant metastases compared to their corresponding primary tumors $(\mathrm{p}<0.001)$, which was especially apparent in patients with clearly positive $(+$ and ++$)$ c-Met staining in the primary tumor (Figs. 1 and 2). Out of $69,30(43.5 \%)$ metastases showed a decreased 
Table III. Degree of immunohistochemical staining for c-Met in primary colorectal adenocarcinomas and in nodal and distant metastases from the same patients.

\begin{tabular}{lccccc}
\hline & \multicolumn{5}{c}{ Degree of immunohistochemical staining } \\
\cline { 2 - 5 } & $-(\%)$ & $+/-(\%)$ & $+(\%)$ & $++(\%)$ & p-value $^{\text {a }}$ \\
\hline Primary tumor & $1(1.4)$ & $12(17.4)$ & $51(73.9)$ & $5(7.2)$ & \\
Nodal metastases & $1(2.8)$ & $2(5.7)$ & $29(82.8)$ & $3(8.6)$ & 0.957 \\
Distant metastases & $3(4.3)$ & $32(46.4)$ & $33(47.8)$ & $1(1.4)$ & $<0.001$ \\
\hline
\end{tabular}

${ }^{a}$ Wilcoxon signed-rank test (non-parametric test for two related samples) comparing metastases with their corresponding primary tumors.
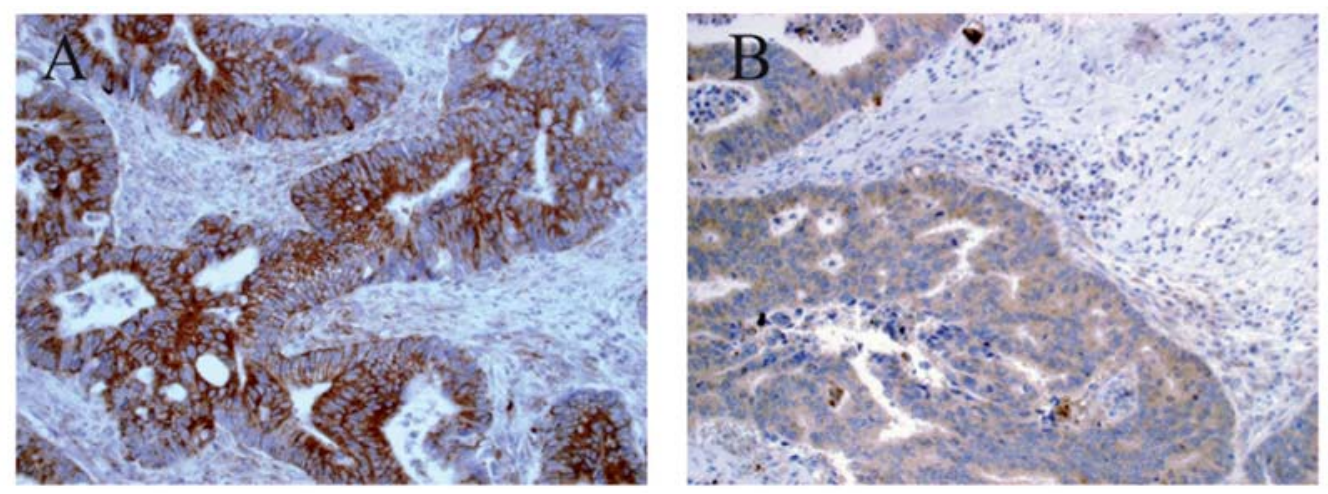

Figure 1. Representative examples of c-Met expression by immunohistochemistry on one primary tumor (A) and its corresponding liver metastasis (B).

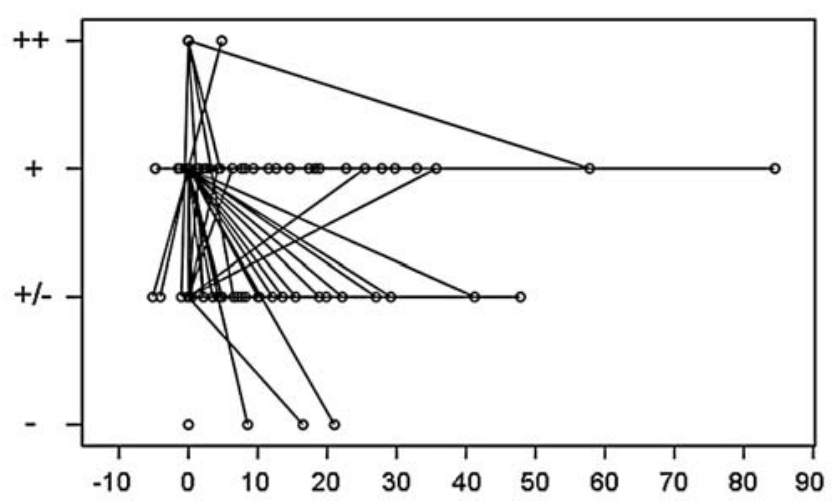

Figure 2. Schematic diagram showing the relationship between c-Met expression in primary colorectal tumors and their corresponding metastases. The $\mathrm{X}$-axis shows the time in months, with 0 indicating the time of primary tumor surgery. Each primary tumor is connected via a line to the time of tissue sampling of its corresponding distant metastasis. The Y-axis shows the immunohistochemical intensity of c-Met expression.

expression compared to their corresponding primary tumors, $7(10.1 \%)$ showed an increased expression, and $32(46.4 \%)$ showed no change. In contrast, lymph node metastases did not differ from their corresponding primary tumors with respect to $c-$ Met expression $(p=0.957)$. Excluding the 10 patients with distant metastasis in the operation scar did not affect the results. The degree of c-Met expression was not related to any of the clinicopathological variables or to the location of the distant metastases (data not shown).

\section{Discussion}

In this study of 69 colorectal cancer patients with disseminated disease, we found that c-Met protein expression tended to be lower in distant metastases compared to their corresponding primary colorectal tumors.

Only two previous small studies have analyzed c-Met expression in primary colorectal tumors and metastases. A study by Otte et al (16) found a high c-Met expression in primary colorectal tumors, whereas only 2 out of 6 liver metastases had detectable c-Met levels. In contrast, Fujita et al (17) reported non-statistically significantly higher c-Met mRNA levels in liver metastasis than in the primary tumor. The down-regulation of c-Met expression in distant metastases has been associated with a more aggressive clinical phenotype in breast (18) and pancreatic cancer (19), which is in line with the findings of the present study. It is possible that c-Met initially enhances the metastatic phenotype of a cancer cell, but becomes down-regulated with the establishment of a distant metastasis, possibly due to different signals from the new microenvironment.

c-Met is a receptor tyrosine kinase which, when stimulated with HGF/SF from stromal cells, becomes autophosphorylated and is thereby activated. Active c-Met signals downstream to stimulate cell proliferation, migration and survival $(11,20)$. The abnormal expression of c-Met and $\mathrm{HGF} / \mathrm{SF}$ in most types of human cancer is associated with poor clinical outcome (11). However, although the expression of c-Met has been extensively studied in human malignancies, 
the significance of phosphorylated c-Met is largely unknown. To our knowledge, only one study has addressed this topic, reporting that the phosphorylation of Y1349 on c-Met is important for tumor growth and progression in renal cell carcinoma (21). It is important to study the activity of receptors such as c-Met, since even low levels of a protein can induce a high level of signal transduction through, for example, heterodimerization or receptor mutations (22). Better phosphospecific antibodies than those currently available are a requirement for such studies. Further investigation of c-Met activation and downstream signaling in primary tumors and their corresponding metastases is needed to determine the importance of c-Met in the metastasis of colorectal cancer.

The main strength of this study is its unique design, including a comparatively large collection of tissue samples from primary colorectal carcinomas and distant metastases from the same patients. The samples were collected according to routine clinical practice over several years, but the time between collection of a primary tumor and its corresponding metastasis seldom exceeded 36 months. This short time minimizes the risk of different conditions for tumors and their metastasis due to changes in protocols for the handling of specimens.

In conclusion, we have demonstrated that c-Met expression is often reduced in distant metastases compared to their corresponding primary colorectal tumors. Additional studies of c-Met activation and signal transduction will increase our knowledge of the role of c-Met in colorectal cancer metastasis.

\section{Acknowledgements}

This study was supported by grants from the Swedish Cancer Foundation and the Cancer Research Foundation in Northern Sweden. The authors would like to thank Mrs. Kerstin Näslund for excellent technical assistance.

\section{References}

1. Hurle RA, Davies G, Parr C, Mason MD, Jenkins SA, Kynaston HG and Jiang WG: Hepatocyte growth factor/scatter factor and prostate cancer: a review. Histol Histopathol 20: 1339-1349, 2005

2. Takanami I, Tanana F, Hashizume T, Kikuchi K, Yamamoto Y, Yamamoto $\mathrm{T}$ and Kodaira S: Hepatocyte growth factor and c-Met/hepatocyte growth factor receptor in pulmonary adenocarcinomas: an evaluation of their expression as prognostic markers. Oncology 53: 392-397, 1996.

3. Alami J, Williams BR and Yeger H: Expression and localization of HGF and met in Wilms' tumours. J Pathol 196: 76-84, 2002.

4. Herynk MH, Stoeltzing O, Reinmuth N, Parikh NU, Abounader R, Laterra J, Radinsky R, Ellis LM and Gallick GE: Down-regulation of c-Met inhibits growth in the liver of human colorectal carcinoma cells. Cancer Res 63: 2990-2996, 2003.
5. Bussolino F, Di Renzo MF, Ziche M, Bocchietto E, Olivero M, Naldini L, Gaudino G, Tamagnone L, Coffer A and Comoglio PM: Hepatocyte growth factor is a potent angiogenic factor which stimulates endothelial cell motility and growth. J Cell Biol 119: 629-641, 1992.

6. Di Renzo MF, Narsimhan RP, Olivero M, Bretti S, Giordano S, Medico E, Gaglia P, Zara P and Comoglio PM: Expression of the Met/HGF receptor in normal and neoplastic human tissues. Oncogene 6: 1997-2003, 1991.

7. Kataoka H, Hamasuna R, Itoh H, Kitamura N and Koono M: Activation of hepatocyte growth factor/scatter factor in colorectal carcinoma. Cancer Res 60: 6148-6159, 2000.

8. Takeuchi H, Bilchik A, Saha S, Turner R, Wiese D, Tanaka M, Kuo C, Wang HJ and Hoon DS: c-MET expression level in primary colon cancer: a predictor of tumor invasion and lymph node metastases. Clin Cancer Res 9: 1480-1488, 2003.

9. Bottaro DP, Rubin JS, Faletto DL, Chan AM, Kmiecik TE, Vande Woude GF and Aaronson SA: Identification of the hepatocyte growth factor receptor as the c-met proto-oncogene product. Science 251: 802-804, 1991.

10. Brinkmann V, Foroutan H, Sachs M, Weidner KM and Birchmeier W: Hepatocyte growth factor/scatter factor induces a variety of tissue-specific morphogenic programs in epithelial cells. J Cell Biol 131: 1573-1586, 1995.

11. Birchmeier C, Birchmeier W, Gherardi E and Vande Woude GF: Met, metastasis, motility and more. Nat Rev Mol Cell Biol 4: 915-925, 2003.

12. Weidner KM, Behrens J, Vandekerckhove J and Birchmeier W: Scatter factor: molecular characteristics and effect on the invasiveness of epithelial cells. J Cell Biol 111: 2097-2108, 1990.

13. De Wever O, Nguyen QD, van Hoorde L, Bracke M, Bruyneel E, Gespach $\mathrm{C}$ and Mareel M: Tenascin-C and SF/HGF produced by myofibroblasts in vitro provide convergent pro-invasive signals to human colon cancer cells through RhoA and Rac. FASEB J 18: 1016-1018, 2004.

14. Hiscox SE, Hallett MB, Puntis MC, Nakamura T and Jiang WG: Expression of the $\mathrm{HGF} / \mathrm{SF}$ receptor, c-met, and its ligand in human colorectal cancers. Cancer Invest 15: 513-521, 1997.

15. Di Renzo MF, Olivero M, Giacomini A, et al: Overexpression and amplification of the met/HGF receptor gene during the progression of colorectal cancer. Clin Cancer Res 1: 147-154, 1995.

16. Otte JM, Schmitz F, Kiehne K, Stechele HU, Banasiewicz T, Krokowicz P, Nakamura T, Folsch UR and Herzig K: Functional expression of HGF and its receptor in human colorectal cancer. Digestion 61: 237-246, 2000.

17. Fujita S and Sugano K: Expression of c-met proto-oncogene in primary colorectal cancer and liver metastases. Jpn J Clin Oncol 27: 378-383, 1997.

18. Bieche I, Champeme MH, Matifas F, Hacene K, Callahan R and Lidereau R: Loss of heterozygosity on chromosome 7q and aggressive primary breast cancer. Lancet 339: 139-143, 1992.

19. Furukawa T, Duguid WP, Kobari M, Matsuno S and Tsao MS: Hepatocyte growth factor and Met receptor expression in human pancreatic carcinogenesis. Am J Pathol 147: 889-895, 1995.

20. Corso S, Comoglio PM and Giordano S: Cancer therapy: can the challenge be MET? Trends Mol Med 11: 284-292, 2005.

21. Miyata Y, Kanetake $H$ and Kanda S: Presence of phosphorylated hepatocyte growth factor receptor/c-Met is associated with tumor progression and survival in patients with conventional renal cell carcinoma. Clin Cancer Res 12: 4876-4881, 2006.

22. Arteaga CL: Epidermal growth factor receptor dependence in human tumors: more than just expression? Oncologist 7: 31-39, 2002 . 